
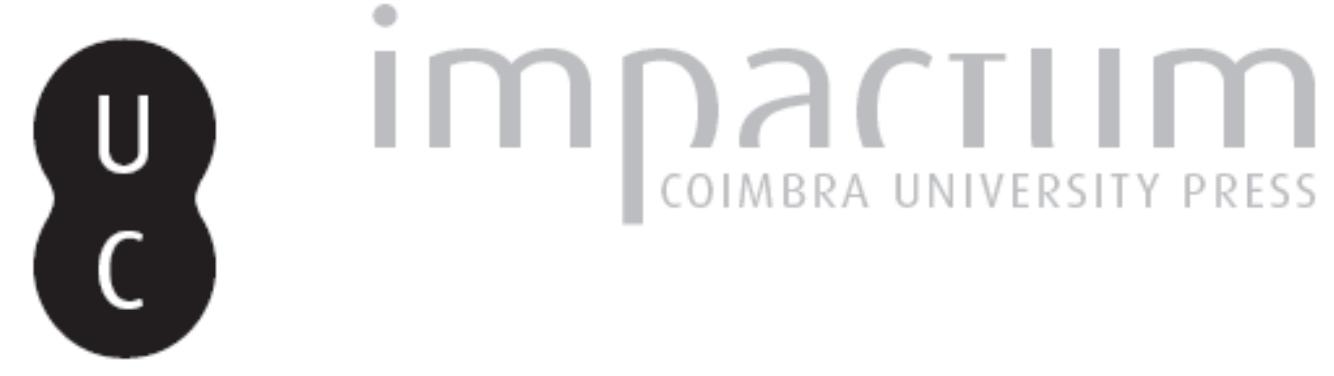

\title{
Apontamentos para a circulação de Boccaccio em Portugal nos séculos XV e XVI: entre a tradição do manuscrito e a inovação do impresso
}

Autor(es): $\quad$ Matos, Manuel Cadafaz de

Publicado por: Imprensa da Universidade de Coimbra

URL persistente:

URI:http://hdl.handle.net/10316.2/42414

DOI:

DOI:https://doi.org/10.14195/0870-8584_9_8

Accessed : $\quad$ 26-Apr-2023 14:19:27

A navegação consulta e descarregamento dos títulos inseridos nas Bibliotecas Digitais UC Digitalis, UC Pombalina e UC Impactum, pressupõem a aceitação plena e sem reservas dos Termos e Condições de Uso destas Bibliotecas Digitais, disponíveis em https://digitalis.uc.pt/pt-pt/termos.

Conforme exposto nos referidos Termos e Condições de Uso, o descarregamento de títulos de acesso restrito requer uma licença válida de autorização devendo o utilizador aceder ao(s) documento(s) a partir de um endereço de IP da instituição detentora da supramencionada licença.

Ao utilizador é apenas permitido o descarregamento para uso pessoal, pelo que o emprego do(s) título(s) descarregado(s) para outro fim, designadamente comercial, carece de autorização do respetivo autor ou editor da obra.

Na medida em que todas as obras da UC Digitalis se encontram protegidas pelo Código do Direito de Autor e Direitos Conexos e demais legislação aplicável, toda a cópia, parcial ou total, deste documento, nos casos em que é legalmente admitida, deverá conter ou fazer-se acompanhar por este aviso.

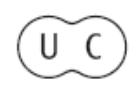




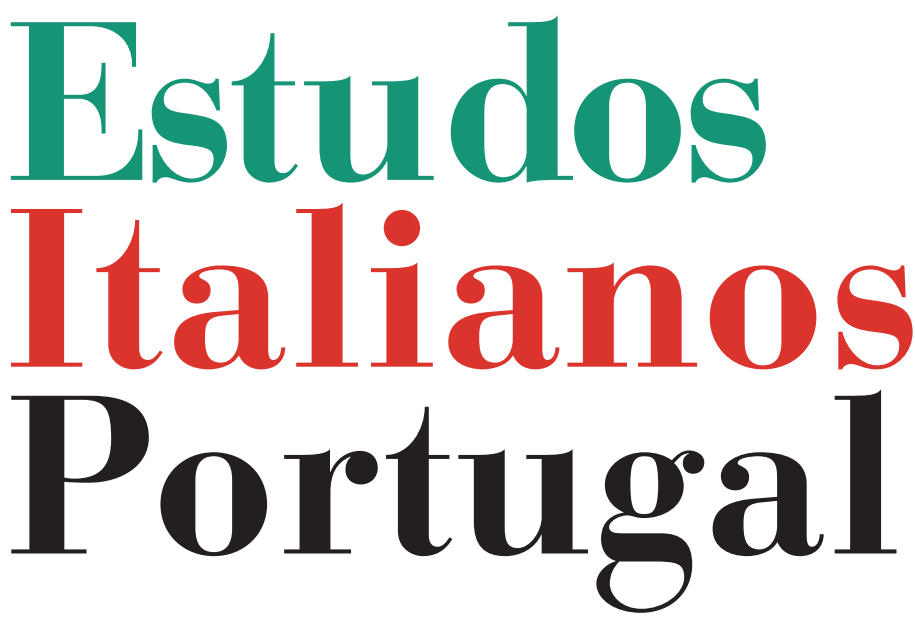

Instituto

Italiano

de Cultura

de Lisboa

Nova Série

$\mathbf{N}^{\circ} 9$ 


\section{APONTAMENTOS PARA A CIRCULAÇÃO DE BOCCACCIO EM PORTUGAL NOS SÉCULOS XV E XVI: ENTRE A TRADIÇÃO DO MANUSCRITO E A INOVAÇÃO DO IMPRESSO}

Manuel Cadafaz de Matos*

AO ESCREVER-SE SOBRE A ENTRADA DE CORRENTES italianistas em Portugal no período quatrocentista, existe habitualmente uma tradição, embora insuficiente, em a centrar no século $\mathrm{XV}$, e em particular na viagem por Itália do Infante D. Pedro (por alturas da década de vinte desse período). Esta influência deve, com efeito, ser alargada a um âmbito mais lato.

Defendemos desde há muito, tal como João Gouveia Monteiro o explicitou também, o espírito de que "a influência cultural italiana em Portugal deve ser apreciada numa óptica mais alargada, que recorde a precocidade das relaçóes comerciais entre os dois países (existentes, pelo menos, desde D. Dinis)" 1 .

É neste contexto, pois, que se inicia a relação do pensador medieval Giovanni Boccaccio - também ele pré-humanista, em alguns textos que prenunciam o aparecimento de uma nova estética literária e no plano das ideias - com o ocidente peninsular e, em particular, com Portugal ou com intelectuais

* Academia Portuguesa da História e CEHLE.

${ }^{1}$ João Gouveia Monteiro, "Orientaçôes da cultura da Corte na 1.a metade do séc. XV (A literatura dos príncipes de Avis)", Vértice, II s., 5, 1988, p. 94. 
portugueses. Assim, no presente estudo, vamos analisar os primórdios da participação desse literato (e de certo modo também pensador) italiano na cultura portuguesa.

A divulgação, ao nível da prática directa do impresso em solo português, das obras de Boccaccio só principiou (documentadamente) com a edição da Fiammetta, mesmo que em língua castelhana, em Lisboa, na oficina de Luís Rodrigues, em $1541^{2}$. Sabendo-se que continua a pairar - mesmo entre investigadores da área de História do Livro - uma significativa nebulosa quanto aos primórdios da difusão das suas obras no ocidente europeu, vamos cingir-nos apenas ao período que medeia entre os fins do século XIV e os fins do século $\mathrm{XV}$, ou seja, até aos limites cronológicos do período incunabular no nosso país.

\section{INFLUÊNCIA NO PANORAMA EDITORIAL PORTUGUÊS NA} TRANSIÇÃO DO PERÍODO MEDIEVAL PARA O RENASCENTISTA

A obra literária e a acção política e diplomática de Boccaccio, entre c. 1340 e Dezembro de 1375 (ano da sua morte, em Certaldo), decorreu sob vários ritmos de produção. Ela conheceu, também, um diversificado conjunto de influências, no plano das ideias estéticas ou mesmo das ideias filosóficas, de que importa destacar a de Petrarca, com quem se correspondeu.

Se, por um lado, foi no Decameron - produzido pouco depois da Peste Negra, que em 1348 assolou não só Florença

\footnotetext{
2 São raríssimos os exemplares que chegaram até aos dias de hoje desta edição portuguesa de 1541. Tal como resultou do estudo analítico desta obra que em 1991 apresentámos em Paris (tornando-se extensiva essa abordagem a aspectos de natureza técnica, como questôes de tipometria e outras quanto à proveniência dos elementos de natureza decorativa), tudo parece indicar que a Inquisição e os seus índices expurgatórios quinhentistas, por a considerarem perniciosa para os leitores, se encarregaram de suprimir a quase totalidade de exemplares da mesma, inspirada em outra, salmantina. Há ed. digitalizada na Biblioteca Nacional do Libro llamado Fiameta.
} 
como amplas regióes da Europa - que ele se revelou, em alguns aspectos, como um literato com ressaibos pré-renascentistas ${ }^{3}$, foi, por outro, já na Fiammetta, de c. 1343-1344, e no Corbaccio, de c. 1354-1355, que ele veio a abrir um significativo percurso como escritor com tendências moralizantes. Essa tendência específica viria a confirmar-se - e a dar dele um dos mais marcantes testemunhos - em duas das mais notáveis obras da maturidade, o De casibus virorum illustrium (que só beneficiou da sua revisão final c. 1374, portanto, a um ano do seu desaparecimento), referente à caída de príncipes em várias fases $\mathrm{da}$ história do homem e do pensamento humano desde o período clássico), e o De claris mulieribus ${ }^{4}$, do mesmo período.

Não deixa de ser curioso assinalar-se que, na Península Ibérica - nomeadamente, em Portugal -, foi (mais do que pela via do Decameron) por estas duas obras que ele seria mais lido, durante o período considerado de códice, ou seja, antes do advento do impresso em Castela, c. de 1472, e no nosso país, em 1489.

Pouco mais de uma dúzia de anos depois do seu desaparecimento, chegavam, estamos em crer, por via do processo de morosos trabalhos de copistas, em particular, à corte de D. João I - e, depois da morte deste, à do rei seu filho D. Duarte (1391-1438), entronizado em 1433 -, exemplares dos De casibus virorum illustrium e De claris mulieribus. Tal ocorreu, de forma conjunta ou separada, na sequência do impulso que havia sido dado nesse sentido, em Castela, pelo chanceler classicista López de Ayala.

Este nobre, recorde-se, depois do desastre castelhano de Aljubarrota - em que participara e onde perdeu alguns den-

${ }^{3}$ António José Saraiva, em História da cultura em Portugal, vol. I, Lisboa, Jornal do Foro, p. 68, considera o Decameron - a par do Conde Lucanor, de D. Juan Manuel, e dos Canterbury Tales, de Chaucer - "das mais interessantes colecções de contos do século XIV".

${ }^{4}$ Existe desde há pouco, na biblioteca do CEHLE, um exemplar de uma edição raríssima desta obra, em versão castelhana, cuja impressão ocorreu na cidade de Sevilha, na oficina de J. Cromberger, em 1528. 
tes -, conhecera vários anos de penosa prisão, primeiro, no castelo de Ourém, e, depois, no de Óbidos 5 . Na segunda destas vilas ${ }^{6}$, escreveu um tratado de cetraria ${ }^{7}$ e terá principiado a congeminar nos seus esforços de tradutor a partir do De casibus..., que principiou, então, ou pouco depois, a escrever.

Tal ocorreu na sequência das múltiplas leituras que aqui teve, inclusivamente quanto a aspectos relacionados com o trabalho de tradução quase integral, para língua castelhana, daquela obra italo-medieval específica. Esta, aliás, passou a circular em códice na península, inclusive em Portugal, pouco depois da data da libertação do seu cativeiro português.

\section{INFLUÊNCIA DE BOCCACCIO NA CORTE DE AVIS ANTES DE 1433 (PARA UM ESTUDO SISTEMÁTICO DA ITALIANÍSTICA QUATROCENTISTA EM PORTUGAL)}

Alguns intelectuais tiveram um papel deveras relevante no desenvolvimento do italianismo no nosso país, ao longo do século XX. Para não explicitarmos outros, poderíamos, em síntese, referenciar os multímodos esforços que, desde a segunda década, desenvolveram investigadores como Joaquim de Carvalho $^{8}, \mathrm{Ri}$ cardo Averini, António José Saraiva, Artur Moreira de Sá, A. D. de Sousa Costa, Giacinto Manuppella, José V. de Pina Martins, Mendes Atanázio, Edurdo Nunes ou, mais recentemente, Rita Marnoto, Manuel Simóes e Vasco Graça Moura.

\footnotetext{
${ }^{5}$ Fernão Lopes, Crónica de D. João I, Porto, Livraria Civilização, sucessivamente reeditada.

${ }^{6}$ Ayala só veio a sair das prisóes desta vila portuguesa, registam os seus principais biógrafos, em 1388, ou já mesmo no primeiro semestre de 1389.

${ }^{7}$ Pedro López de Ayala, Libro de la caza de las aves (Biblioteca virtual Miguel Cervantes).

${ }^{8}$ Em 1921-1923, tinha Joaquim de Carvalho cerca de 29 para 31 anos, fez publicar o seu promissor estudo em torno do tema "Sobre a erudição de Gomes Eanes de Zurara", no Boletim Bibliográfico da Biblioteca da Universidade de Coimbra, 6, 1919-1921, e 7, 1921-1923. Veio a reeditar este trabalho, a par de outros ensaios, na obra Estudos sobre a cultura portuguesa do século XV, vol. I, Coimbra, Por Ordem da Universidade, 1949, pp. 1-241. É esse trabalho de 1921-1923, na secção sobre "Autores
} 
Foi Joaquim de Carvalho (1892-1958) - antecedendo pertinentes trabalhos de António José Saraiva9 - que chamou a atenção para a recepção de Boccaccio em Portugal, ao tempo de D. João I e nos reinados seguintes.

Esse professor conimbricense, detendo-se sobre a circulação dos ideais estéticos e filosóficos do italianismo no século XIV em Portugal e em Castela, conhecia as pesquisas, inovadoras para a época, de Schiff ${ }^{10}$ quanto à influência exercida em intelectuais portugueses por um dos principais agentes culturais peninsulares, em tal período, o 1. ${ }^{\circ}$ Marquês de Santillana (activo, sobretudo, entre Palência e Guadalajara, lugar este da sua imorredoira biblioteca $\left.{ }^{11}\right)$. D. Iñigo de Mendoza (1398-1458) fomentou como poucos, com efeito, o desenvolvimento do pensamento de Dante, Petrarca e Boccaccio

Italianos", e, em particular, sobre Boccaccio (pp. 153-156), que parcelarmente, ou seja, nalguns aspectos, serviu de influência e de incentivo aos nossos esforços de compreensão da circulação de Boccaccio em Portugal ao longo do século XV.

${ }^{9}$ Recordamos o trabalho que com ele publicámos no Diário de Notícias de 17-7-1988, "O Infante D. Henrique só foi um combatente da fé", onde refere que aquele filho de D. João I terá sido "o mais medieval de todos os seus irmãos", alertando-nos para a questão da leitura de Boccaccio pelo infante D. Henrique. Recordamos o Prof. G. Manuppella e os pertinentes ensinamentos de italianística boccacciana que nos transmitiu na correspondência que com ele travámos. Evocamos o saudoso amigo Prof. José Vitorino de Pina Martins e não podemos esquecer a sua habitual generosidade, como ter-nos informado - quando prosseguia, na Fundação Calouste Gulbenkian, a edição das Obras do Prof. Joaquim de Carvalho - deste valioso estudo por aquele Mestre conimbricense sobre a circulação de Boccaccio no século XV no nosso país.

${ }^{10}$ Mario Schiff, La bibliothèque du Marquis de Santillana: étude historique et bibliographique de la collection de manuscripts de Don Iñigo Lopez de Mendoza, Marqués de Santillana, conde del Real de Manzanares, humaniste et auteur espagnol célèbre, Paris, École des Hautes Études, fasc. 153, Paris, Libr. Émile Bouillon, 1905 (reimpressão em Amsterdam, Gérard Theo van Heusden, 1970).

${ }^{11}$ A enorme e qualitativa biblioteca de D. Iñigo de Mendoza foi sendo, nessa primeira metade do século XV, enriquecida com "ofertas, cópias e traduçôes de autores clássicos, medievais, italianos, convertendo-a no modesto berço das novas ideias que o humanismo italiano comunicou a Espanha”. Mario Schiff, cit., pp. LXXXIII e LXXXVI; J. de Carvalho, cit. (1949), pp. 28-29. 
no ocidente europeu. Fê-lo com reflexos directos na cultura portuguesa, como sucedeu, por exemplo, em relação ao condestável D. Pedro, seu amigo pessoal.

As investigações de Mario Schiff vieram a aproveitar a Joaquim de Carvalho, no âmbito de aspectos particulares do boccaccionismo em Castela e Portugal. Tal ocorreu em particular no período de transição do século XV para o século XVI, em termos de enquadramento histórico-literário e filosófico. Deste modo, não se podem separar as pesquisas quer de Schiff quer de Joaquim de Carvalho, entre 1905 e 1923, quanto aos avanços da italianística boccacciana em Castela e Portugal naquele período tardomedieval.

Sobre as relações italianísticas entre Santillana e o Condestável D. Pedro, o douto professor português analisou quer o De casibus... na corte de João I, quer as práticas culturais de recepção, entre nós, de outros textos da fase de maturidade de Boccaccio. E, neste aspecto, importa abordar os resultados de uma importante embaixada castelhana a Lisboa, nessa época.

\section{UMA MISSÃO DIPLOMÁTICA CATELHANA A LISBOA EM $1422 \mathrm{E}$ A CONCLUSÃO DA EDIÇÃO DA CAYDA DE PRINCIPES INICIADA POR AYALA}

Juan Alfonso de Zamora deslocou-se a Portugal no quadro de uma embaixada castelhana, no ano de 1422 (quando foi alterada, por determinação régia, a era ${ }^{12}$ ), em representação do monarca de Castela, D. João II, na companhia de um prelado de alta estirpe, Alonso de Cartagena. São conhecidos dois documentos referentes a essa missão. Em fins de 1421, "El-rei D. João II de Castela manda a Portugal o Dr. Afonso de Cartagena, deão de Santiago e de Segóvia e do seu Conse-

${ }^{12}$ Tal sucedeu por via de um diploma régio joanino de 22-8-1422. Vide "Era", in $E L-B C$, secção "E". Agradecemos esta informação ao nosso confrade na Academia Portuguesa da História, o filósofo Pinharanda Gomes. 
lho, com o escrivão da câmara régia João Afonso de Zamora, responder às duas anteriores embaixadas àquele país". E nos objectivos diplomáticos que se almejavam contava-se que o "Dean concordasse treguas ó paces con ele Rey de Portugal por el menos tiempo que pudiese, con ciertas condiciones [...]"13.

Foi nessa missão diplomática que Alonso de Cartagena aconselhou, aqui, Juan Alfonso de Zamora a concluir a versão para a língua espanhola da referida obra de Boccaccio, na sequência do esforço de Ayala. Não seria um trabalho de grandes dispêndios de tempo, dado que as partes mais substanciais da obra (até ao oitavo capítulo) já tinham sido traduzidas em fins do século pelo erudito chanceler. E o bispo ofereceu-se como escrivão ou copista nesse trabalho.

Por um testemunho coevo, conhecem-se hoje as circunstâncias em que decorreu esse esforço de conclusão da tradução boccacciana de Cayda de Principes:

El porque aquellos que en algunas buenas obras se ocupan siempre nuestro Señor Dios guia. Trajo acaso que en uno el muy reverendo e sabio doctor Alfonso García, Deán de las Iglesias de Santiago e Segovia: Oidor de la Audiencia del dicho Señor Rey, e del consejo: e yo por Embaxadores del dicho Señor Rey de Portugal fuemos enviados: en la qual embaxada como oviesemos algunos espacios para exercitar nuestro espiritu, e veyendo yo la gran suficiencia que en el dicho Deán era para lo romanzar lo que del dicho libro fallescía, e a ruego e instancia mia de se hoponer al trabajo de lo comenzara él plugo.

E conclui tão elucidativo testemunho:

${ }^{13}$ Crónica de D. João II, ano XV, 1421, cap. 34, p. 411; Monumenta Henricina, vol. III, Coimbra, Comissão Executiva das Comemorações do V Centenário da Morte do Infante D. Henrique, 1961, pp. 25-26. Curiosamente, este processo negocial teve a sua conclusão na Primavera de 1423. Sabe-se que em 30 de Abril daquele ano se procedeu à "Ratificação, pelo rei de Castela, D. João II, do Tratado de Paz de 30 de Abril de 1411, celebrado entre Portugal e o país vizinho, na menoridade daquele monarca”. Veja-se, a propósito, a mesma Crónica de D. João II, ano XVII, 1423, cap. 2, p. 423; e Monumenta Henricina, loc. cit., pp. 57-58. 
Y asi de diez libros que hay en este dicho libro, el dicho Señor Pero Lopes [de Ayala] romanzó los ocho hasta la meitad del capitulo que habla del Rey Astur de Inglaterra que es dicha la Grand Bretaña: e Morderete su fijo, e dende en adelante romanzó el dicho Deán, él diciendo, e yo escribiendo, los quales lo hicieron muy bien guardando su Rethorica segund que por él paresce ${ }^{14}$.

Decorreu em Portugal, em tais circunstâncias, a ultimação dessa operosa tradução de Boccaccio na Península Ibérica, como dissemos, em 1422 (cerca de 15 anos depois da morte do autor italiano). Este facto vem trazer, sem dúvida, uma significativa mais-valia à circulação e recepção das obras daquele pré-humanista no nosso país no primeiro quartel do século XV.

\section{OUTROS ASPECTOS DA CIRCULAÇÃO DO DE CASIBUS, APÓS 1433}

Se os testemunhos acerca da leitura dos textos de Boccaccio, na corte de D. João I, ainda se afiguram um tanto tímidos, tal já não sucede quanto aos reinados de D. Duarte e D. Afonso V (1432-1481, governando este depois de 1448, após a Regência do seu tio, o infante D. Pedro).

Foi ainda o Prof. Joaquim de Carvalho quem estudou e transmitiu as primeiras informaçóes sobre a circulação de textos de Boccaccio no tempo de D. Duarte (1391-1438), já após o início do reinado, em 1433, e de D. Afonso V.

Quanto ao reinado de D. Duarte, sabe-se que foi o infante D. Henrique (1394-1460) quem deu testemunho público de ter sido leitor do De casibus. Aconteceu que, em 1437, o infante D. Fernando decidiu participar na expedição enviada a Tânger, comandada pelo infante $\mathrm{D}$. Henrique, a qual teve o voto desfavorável dos infantes D. Pedro, duque de Coimbra, do infante D. João de Portugal, bem como do próprio rei D. Duarte. Foi neste contexto, avaliando os prós e os contras de

${ }^{14}$ Mario Schiff, cit., p. 346; apud Joaquim de Carvalho, cit., pp. 154-155, n. 2. 
tal saída do Reino, que D. Henrique, segundo as crónicas, referiu ao monarca seu irmão, influenciado seguramente por uma leitura de Cayda de Principes, na versão castelhana, que

muitos Reis e Principes com uma longa ociosidade e segurança de paz, nos primeros revezes da fortuna cairam torpemente no mundo de seus estados e senhorios. Os exemplos disto não alego, de que os livros são cheios ${ }^{15}$.

Foi, por outro lado, já na segunda metade do século XV, ainda antes do advento do impresso, que Gomes Eanes de Zurara (1410-1479) se patenteou também como leitor e conhecedor de obras de Boccaccio. Ele havia sido guarda-conservador da Livraria Régia e, cerca de 1451, depois de Fernão Lopes, assumiu a qualidade de Guarda-Mor da Torre do Tombo.

Zurara era, sem dúvida, apreciador das observações de teor moralizante de Cayda de Principes, presumivelmente quanto às partes já traduzidas desse tratado por Ayala ${ }^{16}$. Registou, assim, numa das suas obras cronísticas essenciais, inspirado certamente no De casibus (porventura, servindo-se da mesma versão castelhana), que

a mais exçellente virtude que se pode achar no prinçipe. ss. nas aduersidades seer forte e nas prosperidades umildoso, ca per faleçimento de cada huūa dellas cairam ja muitos prinçipes muy grandes quedas segundo conta Iohan Bocaçio hum poeta que foy natural de Florença ${ }^{17}$.

${ }^{15}$ Rui de Pina, Crónica de D. Duarte, cap. XI; Joaquim de Carvalho, cit., p. 154.

${ }^{16}$ Joaquim de Carvalho, nas notas sobre este tipo de influências dos escritos do pré-humanista italiano, sublinhou, a este respeito, que "Zurara poderia, pois, ter conhecido a obra e o tema de Boccaccio por leitura directa ou de segunda mão, e até mesmo por ouvido numa conversação de letrados. Considerando, porém, as circunstâncias, tudo inculca por mais provável, senão certo, que o cronista leu o De casibus, não no texto latino, mas na tradução castelhana de Pero López de Ayala e Alonso de Cartagena [...]”.

${ }^{17}$ Gomes Eanes de Zurara, Crónica da tomada de Ceuta, pp. 14-15. 
5. O CÓDICE IOAN BOCACI, NA BIBLIOTECA DO CONDESTÁVEL, TRADUZ UMA VERTENTE DO BOCCACCIONISMO NA CULTURA PORTUGUESA DOS SÉCS. XIV E XV

Ao longo de anos de estudos sobre a circulação das ideias literárias e filosóficas italianas em Portugal desde fins da Idade Média, continua a constituir nossa firme convicção, por outro lado, que o Ioan Bocaci, que integrou a biblioteca do filho do infante D. Pedro - de quem herdara sólida formaçãoo ${ }^{18}-$, o condestável D. Pedro ${ }^{19}$, candidato a conde de Barcelona nas lutas desenvolvidas entre 1463 e 1466 , ano da sua morte ${ }^{20}$, mais não era do que um exemplar do De casibus. Tal códice fora-lhe oferecido pelo Marquês de Santillana, que o infante português - com quem se correspondeu ${ }^{21}$ - considerava amigo e Mestre.

Quanto à identificação desse Ioan Bocaci em castelhano integrando um fundo bibliográfico português (entre outros códices de pendor moralizante), subsiste hoje, no nosso espírito, apenas uma dúvida. Isto é, em que condições decorreu a sua incorporação nessa biblioteca do condestável - em cujo catálogo figurava sob a rubrica 92 -, já depois, portanto, de ele ter chegado à região catalâ.

${ }^{18}$ Remetemos para o nosso estudo "O Infante D. Pedro, a versão do De Officiis e outras preocupaçôes ciceronianas no ocidente europeu do século XV", Biblos, 69, 1993 (Actas do Congresso sobre o Infante D. Pedro), pp. 315-341.

${ }^{19}$ Sousa Viterbo, A litteratura hespanhola em Portugal, p. 166.

${ }^{20}$ O condestável D. Pedro (1429-1466) era filho do infante D. Pedro e neto, por via materna, do catalão D. Jaime II de Urgel. Foi essa relação familiar que o levou em 1463 a deixar o Reino de Portugal e ir para a região de Barcelona, lutar no plano do direito sucessório, em fidelidade às suas convicçōes políticas. Quiseram os acontecimentos que tenha falecido três anos depois, apenas com 37 anos de idade, sem conseguir o reconhecimento real dos seus intentos.

${ }^{21} \mathrm{Da}$ autoria desse I Marquês de Santillana (que também esteve na origem da histórica Biblioteca de Osuna) é o Proemio e Carta al Condestavel D. Pedro de Portugal. Esse texto permite um melhor conhecimento dos aspectos relacionais entre esses dois amigos peninsulares, unidos também em aspectos particulares dos estudos da italianística, e de Boccaccio, em particular. 
Poderá ter-se tratado, a nosso ver, de um códice com a cópia da obra De casibus / Cayda de Principes, onde já se encontravam reunidas a ampla versão dos oito primeiros capítulos, feita pelo erudito chanceler Ayala - que entretanto havia falecido em Calahorra, em 1407 (com c. de 75 anos de idade) -, e a versão complementar dos últimos capítulos feita por Juan Alfonso de Zamora, secretário de D. Juan II. Nas investigações que temos em curso sobre documentação existente em Barcelona e em Guadalajara, procuramos encontrar resposta(s) a estas duas questôes.

Essa nossa convicção de se tratar do códice Cayda de Principes afigura-se com muito maior grau de probabilidade do que ser um outro, do mesmo autor. De facto, poderia, também, apresentar-se nele uma cópia da tradução, pelo catalão Bernat Metge, do último conto do Decameron, a história de Griselda, numa iniciativa realizada por aquele (a partir da versão latina feita por Petrarca do mesmo texto), que havia sido finalizada por aquele em 1388. Não se nos afigura, porém, como muito verosímil esta outra hipótese.

A filiação do espírito do condestável D. Pedro no referido texto do pré-humanista florentino foi testemunhado claramente por esse aristocrata e homem de cultura, quando, numa das suas obras, escreveu sobre a forma de os nobres deverem estar moralizados quanto a quedas dos grandes, pensando em exemplos específicos das suas desventuras:

ca no son llenos los libros e coronicas salvo de muertes e de caydas de principes e cavalleros... ${ }^{22}$

Esse último aspecto da influência do tratado Cayda de Principes no pensamento do condestável D. Pedro prende-se com o da ampla circulação de outros dos principais tratados

${ }^{22}$ Condestável D. Pedro, Tragedia de la insigne reyna Doña Isabel, Coimbra, Imprensa da Universidade, 1922. 
I32 Manuel Cadafaz de Matos

da fase de maturidade de Boccaccio, no Portugal de antes da introdução da imprensa. 